\title{
FOXN3 is downregulated in osteosarcoma and transcriptionally regulates SIRT6, and suppresses migration and invasion in osteosarcoma
}

\author{
WENTAO XUE ${ }^{1}$, LINJIE MA ${ }^{1}$, ZHIQIAN WANG ${ }^{1}$, WEIDONG ZHANG ${ }^{2}$ and XIUGONG ZHANG ${ }^{3}$ \\ ${ }^{1}$ Department of Orthopedics, Yidu Central Hospital of Weifang, Weifang, Shandong 262500; \\ ${ }^{2}$ Department of Orthopedics, Yantai Hospital of Traditional Chinese Medicine, Yantai, Shandong 264000; \\ ${ }^{3}$ Department of Orthopedics, Qingdao Central Hospital, Qingdao, Shandong 266042, P.R. China
}

Received January 18, 2018; Accepted November 8, 2018

DOI: $10.3892 /$ or.2018.6878

\begin{abstract}
Forkhead box N3 (FOXN3) has been reported to be downregulated in numerous cancers, including laryngeal, oral squamous cell and hepatocellular carcinomas, and diffuse large B-cell lymphoma. FOXN3 was proposed to serve as a tumor suppressor; however, the function of FOXN3 in osteosarcoma (OS) remains unknown. The present study suggested that FOXN3 was notably downregulated in OS tissues compared with in adjacent normal tissues, and the expression of FOXN3 was negatively correlated with tumor size, metastasis and tumor, node and metastasis stage. Additionally, low expression levels of FOXN3 predicted a poor prognosis of patients with OS. Additionally, the present study revealed that FOXN3 was also downregulated in OS cells. Numerous functional experiments, including colony formation, Cell Counting Kit-8, wound healing and Transwell invasion assays, were performed. The results of the present study revealed that FOXN3 suppressed the proliferation, migration and invasion of OS cells. SIRT6 has been reported to serve a key role in OS; chromatin-immunoprecipitation (ChIP) and quantitative ChIP, as well as a luciferase reporter assay, demonstrated that SIRT6 was transcriptionally regulated by FOXN3. Furthermore, FOXN3 also regulated matrix metalloproteinase-9 secretion via the regulation of SIRT6 expression. The findings of the present study indicated that FOXN3 serves as a tumor suppressor in OS and proposed FOXN3 as a prognostic predictor and a therapeutic target for patients with OS.
\end{abstract}

Correspondence to: Dr Weidong Zhang, Department of Orthopedics, Yantai Hospital of Traditional Chinese Medicine, 39 Xingfu Road, Yantai, Shandong 264000, P.R. China

Email: zhangweidonga@yeah.net

Dr Xiugong Zhang, Department of Orthopedics, Qingdao Central Hospital, 127 Siliunan Road, Qingdao, Shandong 266042, P.R. China E-mail: Zhang88asl@163.com

Key words: forkhead box N3, sirtuin 6, migration, invasion, osteosarcoma

\section{Introduction}

Osteosarcoma (OS) has been reported as one of the most common aggressive types of bone tumor (1). Children and young adults $(<20$-years-old) exhibit a high incidence of OS (2). In the past decades, with the application of neoadjuvant chemotherapy using doxorubicin, cisplatin, doxorubicin and ifosfamide in OS treatment, the 5-year survival rate has increased to $\sim 50-80 \%(3,4)$; however, the prognosis of OS remains poor and the majority of patients succumb to mortality due to metastases following surgical resection or intensive chemotherapy (5-7). Therefore, it is necessary to identify a sensitive molecular biomarker and therapeutic target for the treatment of OS.

Forkhead box N3 (FOXN3), also known as checkpoint suppressor 1, was first reported in yeast as a suppressor of check point defects (8). FOXN3 belongs to the forkhead box family, a novel family of transcription factors. The FOX family has been classified into 15 subclasses, including FOXA and FOXS (9). Numerous studies have demonstrated the physiological roles of FOXN3 in embryonic development $(10,11)$. Previous investigations revealed that FOXN3 expression was notably downregulated in numerous cancer tissues compared with in adjacent non-cancerous tissues, including laryngeal, oral squamous cell and hepatocellular carcinomas, and diffuse large B-cell lymphoma (12-16). This evidence indicates that FOXN3 may serve a key function in cell proliferation and apoptosis within human cancer via the regulation of gene transcription. Similar to other members of the forkhead transcription factors, FOXN3 has also been reported to bind with several nuclear proteins, including histone deacetylase (HDAC)1, HDAC2 and multiple endocrine neoplasia type 1 (9). Previously, it was demonstrated that FOXN3 regulated cell proliferation by suppressing PIM2 and protein biosynthesis (17), or by downregulating E2F transcription factor 5 (E2F5) in human cells to control the cell cycle (9); however, the function and underlying mechanisms of FOXN3 in OS is poorly understood.

Sirtuin 6 (SIRT6) belongs to the SIRT family of proteins and has been notably identified as a critical regulator in a variety of physiological and pathological processes, including 
life span, glucose metabolism, DNA damage repair and cancer (18). SIRT6 has been reported to deacetylate histone $\mathrm{H} 3 \mathrm{~K} 9$ at the promoter of numerous genes involved in lipid metabolism and glycolysis (19). A recent study revealed that SIRT6 contributes to the migration and invasion of OS cells via the extracellular signal-regulated kinase (ERK)1/2/matrix metalloproteinase-9 (MMP-9) pathway (20); however, the upstream molecules of SIRT6 signaling in OS remains unknown.

The present study demonstrated that FOXN3 was downregulated in OS tissues and cell lines. In addition, the expression of FOXN3 was negatively associated with tumor size, metastasis and tumor, node and metastasis (TNM) stage. The results of the present study suggest that FOXN3 suppressed the proliferation, migration and invasion of OS cells. Furthermore, FOXN3 was proposed to transcriptionally suppresses SIRT6 expression, thereby inhibiting MMP-9 secretion. Therefore, FOXN3 may serve as a prognostic predictor and a therapeutic target for patients with OS.

\section{Materials and methods}

Cell culture. Human OS cell lines, including U2OS and MG-63, and the osteoblast cell line, hFOB1.19, were purchased from the American Type Culture Collection (Manassas, VA, USA). All cells were cultured in Dulbecco's modified Eagle's medium (DMEM; HyClone; GE Healthcare Life Sciences, Logan, UT, USA) supplemented with $100 \mathrm{U} / \mathrm{ml}$ penicillin and $100 \mu \mathrm{g} / \mathrm{ml}$ streptomycin, and fetal bovine serum (10\%; HyClone; GE Healthcare Life Sciences). Cell were cultured in an incubator containing $5 \% \mathrm{CO}_{2}$ humidified atmosphere at $37^{\circ} \mathrm{C}$.

Clinical samples. A total of 78 pairs of clinical OS and adjacent normal tissue specimens were obtained from patients who were diagnosed with OS in the Department of Orthopedics, Yidu Central Hospital of Weifang (Weifang, China) during 2010 to 2016. A total of 45 males and 33 females aged between 12-28-years-old, with a mean age of 18.4 years were employed in the present study. All tissues were obtained prior to the administration of immunotherapy, chemotherapy or radiotherapy. The majority of the obtained samples $(>86 \%)$ were collected between 2010 to 2013. The survival data of some patients were of $<5$ years; however, the majority of patients' survival data were of 5 years. All patients had provided written informed consent. The present study was approved by the Research Ethics Committee of Yidu Central Hospital of Weifang (LK2017012). All specimens were stored in liquid nitrogen prior to use.

Transfection. A total of $\sim 5 \times 10^{5}$ U2OS or MG-63 cells were placed into 6-well plates and incubated for $24 \mathrm{~h}$ at $37^{\circ} \mathrm{C}$. Subsequently, cells were transfected with $2.5 \mu \mathrm{g}$ vector (pcDNA3.1), pcDNA3.1-FOXN3 and/or pcDNA3.1-SIRT6 or $50 \mathrm{nM}$ small interfering (si)RNAs using Lipofectamine ${ }^{\circledR} 2000$ reagent (Invitrogen, Thermo Fisher Scientific, Inc., Waltham, MA, USA) according to the manufacturer's protocols. After transfection for $48 \mathrm{~h}$, successful transfection was determined using reverse transcription-quantitative polymerase chain reaction (RT-qPCR) and western blot analyses. The vector
(pcDNA3.1), pcDNA3.1-FOXN3 and pcDNA3.1-SIRT6 were purchased from Vigene Biosciences, Inc. (Rockville, MD, USA). The human FOXN3 and SIRT6 gene sequences were retrieved from the NCBI gene bank (https://www.ncbi.nlm. nih.gov/nuccore; NM_001085471 and NM_001193285.2, respectively) SiRNAs were purchased from Sigma-Aldrich (Merck KGaA, Darmstadt, Germany). The sequence of the siRNAs was as follows: SiFOXN3, 5'-GUACCUUCUUCA AGAGAAAUG-3' and scramble siRNA (siControl), 5'-UUC UCCGAACGUGUCACGU-3'.

$R T-q P C R$. Total RNA was extracted from tissues or cells by using TRIzol ${ }^{\circledR}$ reagent (Invitrogen; Thermo Fisher Scientific, Inc.) according to the manufacturer's protocols. Subsequently, $2 \mu \mathrm{g}$ RNA was used to synthesize cDNA using SuperScript III Reverse Transcriptase kit (Invitrogen; Thermo Fisher Scientific, Inc.). The reverse transcription conditions were as follows: $5 \mathrm{~min}$ at $25^{\circ} \mathrm{C}, 30 \mathrm{~min}$ at $50^{\circ} \mathrm{C}$ and $15 \mathrm{~min}$ at $70^{\circ} \mathrm{C}$. Finally, qPCR was conducted using the SYBR Fast qPCR kit (Takara Bio, Inc., Otsu, Japan) on an ABI 7500 system (Applied Biosystems; Thermo Fisher Scientific, Inc.). The RT-qPCR conditions were as follows: $5 \mathrm{~min}$ at $98^{\circ} \mathrm{C}$, denaturation at $98^{\circ} \mathrm{C}$ for $30 \mathrm{sec}$, annealing at $55^{\circ} \mathrm{C}$ for $30 \mathrm{sec}$ and extension at $72^{\circ} \mathrm{C}$ for $20 \mathrm{sec}$, performed for 30 cycles. The primers were as follows: FOXN3 forward, 5'-CCCTTCTCC AAGATCCTGAC-3', reverse, 5'-GCTGTAGTTGTGATCCTC CT-3'; SIRT6 forward, 5'-GTTCGACACCACCTTTGAG-3', reverse, 5'-ACGTACTGCGTCTTACAC-3' and GAPDH forward, 5'-ATTTCCTGGTATGACAACGA-3' and reverse, 5'-GGAGATTCAGTGTGGTGG-3'. GAPDH was used as an internal control. Each experiment was performed in triplicate. As presented in Table I, the mean value of FOXN3 mRNA expression in tumor cells considered as the standard; higher values than the standard was denoted as high expression and values lower than the standard values were considered as low expression. The stage of OS was according to tumor, node and metastasis (TNM) staging system (21). The relative gene expression was measured using $2^{-\Delta \Delta \mathrm{Cq}}$ method (22).

Western blotting. Total protein was extracted from tissues and cells using radioimmunoprecipitation assay lysis buffer (Beyotime Institute of Biotechnology, Haimen, China). The concentration of protein was measured via a Bicinchoninic Acid (BCA) protein assay kit (Beijing Solarbio Science \& Technology Co., Ltd., Beijing, China) according to the manufacturer's protocols. Protein samples $(45 \mu \mathrm{g})$ were loaded and then separated by $10 \%$ SDS-PAGE, and then the protein was transferred to polyvinylidene difluoride membranes (Merck $\mathrm{KGaA}$ ). The membranes were blocked with 5\% skimmed milk at room temperature for $1 \mathrm{~h}$ and then incubated with primary antibodies at $4^{\circ} \mathrm{C}$ overnight. Following washing with PBS with $0.1 \%$ Tween-20 (PBST) three times, the membranes were incubated with horseradish peroxidase (HRP)-conjugated second antibodies at room temperature for $1 \mathrm{~h}$ and washed with PBST three times. The blots were identified using Western Blotting Luminol Reagent (Santa Cruz Biotechnology, Inc., Dallas, TX, USA). The anti-FOXN3 polyclonal antibody $(1: 2,000 ; \mathrm{ab} 50756)$ and anti-SIRT6 polyclonal antibody (1:1,000; ab62739), HRP-conjugated anti-rabbit antibody (1:5,000; ab6721) and HRP-conjugated anti-mouse antibody (1:5,000; ab6789) were 
Table I. Clinicopathological variables in 78 patients with osteosarcoma.

FOXN3 protein expression

\begin{tabular}{|c|c|c|c|c|}
\hline \multirow{2}{*}{ Variables } & \multirow[b]{2}{*}{ Patient no. $(n=78)$} & & \multirow[b]{2}{*}{ P-value } \\
\hline & & Low $(n=43)$ & High $(n=35)$ & \\
\hline \multicolumn{5}{|l|}{ Sex } \\
\hline Male & 45 & 23 & 22 & 0.405 \\
\hline Female & 33 & 20 & 13 & \\
\hline \multicolumn{5}{|l|}{ Age } \\
\hline$<18$ & 50 & 30 & 20 & 0.248 \\
\hline$\geq 18$ & 28 & 13 & 15 & \\
\hline \multicolumn{5}{|l|}{ Tumor size } \\
\hline$<8 \mathrm{~cm}$ & 42 & 14 & 28 & $0.001^{\mathrm{a}}$ \\
\hline$\geq 8 \mathrm{~cm}$ & 36 & 29 & 7 & \\
\hline \multicolumn{5}{|l|}{ TNM stage } \\
\hline I-III & 44 & 19 & 25 & $0.016^{\mathrm{a}}$ \\
\hline IV & 34 & 24 & 10 & \\
\hline \multicolumn{5}{|l|}{ Metastasis } \\
\hline Yes & 42 & 30 & 12 & $0.002^{\mathrm{a}}$ \\
\hline No & 36 & 13 & 23 & \\
\hline \multicolumn{5}{|c|}{ SIRT6 expression } \\
\hline High & 42 & 33 & 9 & $0.001^{\mathrm{a}}$ \\
\hline Low & 36 & 10 & 26 & \\
\hline
\end{tabular}

SIRT6, sirtuin 6. ${ }^{\mathrm{a}} \mathrm{P}<0.05$.

purchased from Abcam (Cambridge, UK). The anti- $\beta$-actin antibody (1:5,000; A3854) was purchased from Sigma-Aldrich (Merck KGaA).

Cell counting kit-8 (CCK-8) assay. A CCK-8 assay was used to investigate the roles of FOXN3 on cell proliferation. Briefly, $\sim 3,000$ transfected cells were resuspended in $200 \mu \mathrm{l}$ DMEM and placed into 96-well plates; $20 \mu \mathrm{l} \mathrm{CCK-8} \mathrm{reagent} \mathrm{(Beyotime}$ Institute of Biotechnology) was added to each subset well at 0, 24, 48 and $72 \mathrm{~h}$. Cells were cultured at $37^{\circ} \mathrm{C}$ for $1 \mathrm{~h}$. The optical density was quantitated at $450 \mathrm{~nm}$ using a microplate reader. Each experiment was performed in triplicate.

Colony formation assay. A colony formation assay was performed to determine the effects of FOXN3 on cell proliferation. In brief, $\sim 5 \times 10^{3}$ transfected U2OS and MG-63 cells with serum-free DMEM were plated in 6-well plates, and cultured for 14 days at $37^{\circ} \mathrm{C}$. Cells were fixed with $4 \%$ paraformaldehyde solution at room temperature for $15 \mathrm{~min}$ and stained with $0.5 \%$ w/v crystal violet (Sigma-Aldrich; Merck $\mathrm{KGaA}$ ) at room temperature for $15 \mathrm{~min}$. Colonies (>50 cells) were counted under a light microscope (magnification, x20). A total of 5 random fields were analyzed. Each experiment was performed in triplicate.

Wound healing analysis. Following transfection for $48 \mathrm{~h}$, cells were plated into 24 -well plates. Wound healing analysis was performed to determine the effects of FOXN3 on the migration of U2OS and MG-63 cells. In brief, cells at
$90 \%$ confluence were wounded with a $10-\mu 1$ sterile pipette tip, washed with PBS three times to remove the detached cells, and cultured in serum-free DMEM at $37^{\circ} \mathrm{C}$. Following wounding for $48 \mathrm{~h}$, the images were captured under a light microscope (magnification, x20). The migratory distance was measured using Image-Pro Plus software 6.0 (Media Cybernetics, Inc., Rockville, MD, USA). Each experiment was performed in triplicate.

Transwell invasion assay. In brief, Transwell chambers (Corning Costar; Corning Incorporated, Corning, NY, USA) were coated with $80 \mu \mathrm{l}$ Matrigel and warmed at $37^{\circ} \mathrm{C}$ prior to use. Transfected U2OS and MG-63 cells ( $\left.2 \times 10^{5}\right)$ were resuspended in $500 \mu \mathrm{l}$ serum-free DMEM and placed in the upper chambers. The lower chambers were filled with $500 \mu 1$ DMEM supplemented with $10 \% \mathrm{FBS}$. The cells were incubated at $37^{\circ} \mathrm{C}$ for $18 \mathrm{~h}$. The cells on the surface of the chamber were removed with a swab and then stained with $0.1 \%$ crystal violet at room temperature for $15 \mathrm{~min}$. The number of cells on the underlayer of chamber were counted under a light microscope (magnification, $\mathrm{x} 20$ ); 5 random fields were analyzed. Each experiment was performed in triplicate.

Chromatin immunoprecipitation (ChIP) and quantitative ( $q$ ChIP) assays. ChIP analysis was performed using a ChIP Assay kit (Beyotime Institute of Biotechnology) according to manufacturer's protocols. Briefly, U2OS and MG-63 cells were cultured to $90-100 \%$ confluence, and washed with cold-PBS three times and chemically cross-linked with 
$1 \%$ formaldehyde at $37^{\circ} \mathrm{C}$ for $30 \mathrm{~min}$. Subsequently, cells were lysed with $2 \mathrm{ml}$ lysis buffer at $4^{\circ} \mathrm{C}$ for $90 \mathrm{~min}$ and sonicated under $4 \times 15$ times at $4^{\circ} \mathrm{C}$. FOXN3 antibody (1:200, ab50756, Abcam) and anti-rabbit $\operatorname{IgG}(1: 200$, ab171870, Abcam) were added to the lysis solution and incubated at $4{ }^{\circ} \mathrm{C}$ overnight. Protein A beads were used to isolate FOXN3- or IgG-interacted DNA fragments. Following elution with $120 \mu$ l elution buffer ( $10 \%$ SDS, $10 \% 1 \mathrm{M} \mathrm{NaHCO}_{3}, 80 \% \mathrm{ddH}_{2} \mathrm{O}$ ), crosslinking was reversed with elution buffer containing $0.2 \mathrm{M} \mathrm{NaCl}$ and $2 \mu \mathrm{l}$ RNase A (10 mg/ml; Sigma-Aldrich; Merck KGaA) at $65^{\circ} \mathrm{C}$ overnight. After incubation with $4 \mu \mathrm{l}$ proteinase $\mathrm{K}(10 \mathrm{mg} / \mathrm{ml}$; Sigma-Aldrich; Merck KGaA) at $60^{\circ} \mathrm{C}$ for $1 \mathrm{~h}$, the bound chromatin was purified using a PCR Purification kit (Qiagen, Inc., Valencia, CA, USA) according to manufacturer's protocols, and qPCR was performed. The qPCR conditions were as follows: $5 \mathrm{~min}$ at $98^{\circ} \mathrm{C}$, denaturation at $98^{\circ} \mathrm{C}$ for $30 \mathrm{sec}$, annealing at $55^{\circ} \mathrm{C}$ for $30 \mathrm{sec}$ and extension at $72^{\circ} \mathrm{C}$ for $20 \mathrm{sec}$, performed for 30 cycles. The primer sequences were as follows: SIRT6 forward, 5'-AATAAGAAGGGCCTGATGGC-3', reverse, 5'-TGTATGTGGGAGAAAGAAGC3' and E2F transcription factor 5 (E2F5) forward, 5'-TCTTCAGCAGGATCTATTAG TGG-3' and reverse: 5'-TGTAGTCATCTGCCGGGGTA-3'. IgG was used as internal control; E2F was used as positive control (9). Each experiment was performed in triplicate.

Luciferase reporter assay. The promoter region $(-2000,+200)$ of SIRT6 was cloned into pGL3-basic plasmid (Biofeng, Beijing, China). U2OS and MG-63 cells $\left(5 \times 10^{5}\right)$ were seeded in 6-well plates and transfected with vector or pcDNA3.1-FOXN3 $(0,0.5,1$ or $2 \mu \mathrm{g})$, together with $1 \mu \mathrm{g}$ pGL3-basic plasmid or pGL3-SIRT6 and $0.5 \mu \mathrm{g}$ Renilla plasmid (Promega Corporation, Madison, WI, USA) using Lipofectamine ${ }^{\circledR} 2000$ reagent (Invitrogen, Thermo Fisher Scientific, Inc.). Following transfection for $24 \mathrm{~h}$, Renilla luciferase and firefly activities were determined using a dual-luciferase reporter system (Promega Corporation) according to the manufacturer's protocols. Renilla luciferase was used as internal control. Each experiment was performed in triplicate.

ELISA. Briefly, after transfection for $48 \mathrm{~h}$, cells were seeded into 6 -well plates at a density of $3 \times 10^{5}$ cells/well with serum-free DMEM. Cell culture supernatants were harvested $72 \mathrm{~h}$ later, and centrifuged at 2,000 $\mathrm{xg}$ for $15 \mathrm{~min}$ at $4^{\circ} \mathrm{C}$. The effects of FOXN3 on the secretion of MMP-2 and MMP-9 into the supernatant from U2OS and MG-63 cells were determined using corresponding ELISA kits (cat. nos. CSB-E04675h and CSB-E08006h; Cusabio, Wuhan, China) according to the manufacturer's protocols. Each experiment was performed in triplicate.

Gelatin zymography. Secreted MMPs in conditioned medium (serum-free DMEM) were affinity-adsorbed with gelatin-Sepharose as previously described (23). The concentration of protein was measure using a BCA protein assay kit (Beijing Solarbio Science \& Technology Co., Ltd.). SDS sample buffer lacking dithiothreitol was added and proteins $(10 \mu \mathrm{g} / \mathrm{ml})$ were resolved on $10 \%$ acrylamide, SDS gels contained polymerized gelatin $(0.5-2 \mathrm{mg} / \mathrm{ml})$. MMPs were renatured via two detergent exchange washes $(2.5 \%$ Triton $\mathrm{X}-100,50 \mathrm{mM}$ Tris $\mathrm{HCl}, 5 \mathrm{mM} \mathrm{CaCl}_{2}, 1 \mu \mathrm{M} \mathrm{ZnCl}_{2} ; 1 \%$ Triton X-100, $50 \mathrm{mM}$ Tris
$\mathrm{HCl}, 5 \mathrm{mM} \mathrm{CaCl} 2,1 \mu \mathrm{M} \mathrm{ZnCl}_{2}$ ). Gels were incubated for $48 \mathrm{~h}$ at $23^{\circ} \mathrm{C}$ for MMP-mediated degradation of gelatin, which was followed by staining with Coomassie brilliant blue at room temperature for $1 \mathrm{~h}$. Gels were destained with destaining solution $\left(40 \%\right.$ methanol, $50 \%$ acetic acid, $\left.10 \% \mathrm{ddH}_{2} \mathrm{O}\right)$ at room temperature, and scanned and inverse images were quantified using ImageJ software 1.8.0 (National Institutes of Health, Bethesda, MD, USA), with relative grayscale values for MMP-9 normalized to cell lysate FOXN3/ $\beta$-actin ratios.

Statistical analysis. Data were presented as the mean \pm standard deviation. Prism 5 software (GraphPad Software, Inc., La Jolla, CA, USA) was used for statistical analysis. Comparisons between cancer and adjacent normal tissue were performed using a paired-samples t-test based on a bi-directional hypothesis for continuous variables. The Kaplan-Meier method and a log-rank test were used to analyze survival curves. A Student's t-test was applied to analyze the differences between two groups. Differences between multiple groups were analyzed by analysis of variance followed by a Tukey's post hoc test. $\mathrm{P}<0.05$ was considered to indicate a statistically significant difference.

\section{Results}

FOXN3 expression is significantly downregulated in OS. To determine the expression profile of FOXN3 in OS, 78 pairs of OS and adjacent normal tissues were obtained to detect the expression of FOXN3 by RT-qPCR and western blotting. The results of RT-qPCR and western blotting revealed that the mRNA levels of FOXN3 were significantly downregulated in tumor tissues, compared with adjacent normal tissues; the protein expression levels were notably downregulated in the OS tissues compared with in the adjacent normal samples (Fig. 1A). In addition, the association between the expression of FOXN3 and the clinical information of patients with OS was analyzed, which demonstrated that the expression of FOXN3 was negatively correlated with tumor size, metastasis and TNM stage (Table I). These findings indicated that FOXN3 may serve as a tumor suppressor in OS.

Additionally, the present study analyzed whether FOXN3 expression was associated with the prognosis of OS via Kaplan-Meier analysis. The results suggested that patients who possessed high expression levels of FOXN3 exhibited better prognosis than patients with low FOXN3 expression levels $(\mathrm{P}=0.041$; Fig. 1B). Furthermore, the expression of FOXN3 in OS cells (U2OS and MG-63) was examined. The osteoblast cell line hFOB1.19 was used as a control. Similar results were observed to that of OS and adjacent normal tissues. The expression levels of FOXN3 were significantly lower in U2OS and MG-63 cells compared with in hFOB1.19 cells (Fig. 1C). Collectively, these data indicated that FOXN3 expression is downregulated in OS and may serve as a tumor suppressor.

FOXN3 inhibits the proliferation of OS cells. To evaluate the roles of FOXN3 in the progression of OS, FOXN3 was ectopically expressed or downregulated in U2OS and MG-63 cells; the expression of FOXN3 was analyzed via RT-qPCR and western blotting. The mRNA expression levels of FOXN3 in the overexpression group were significantly upregulated 

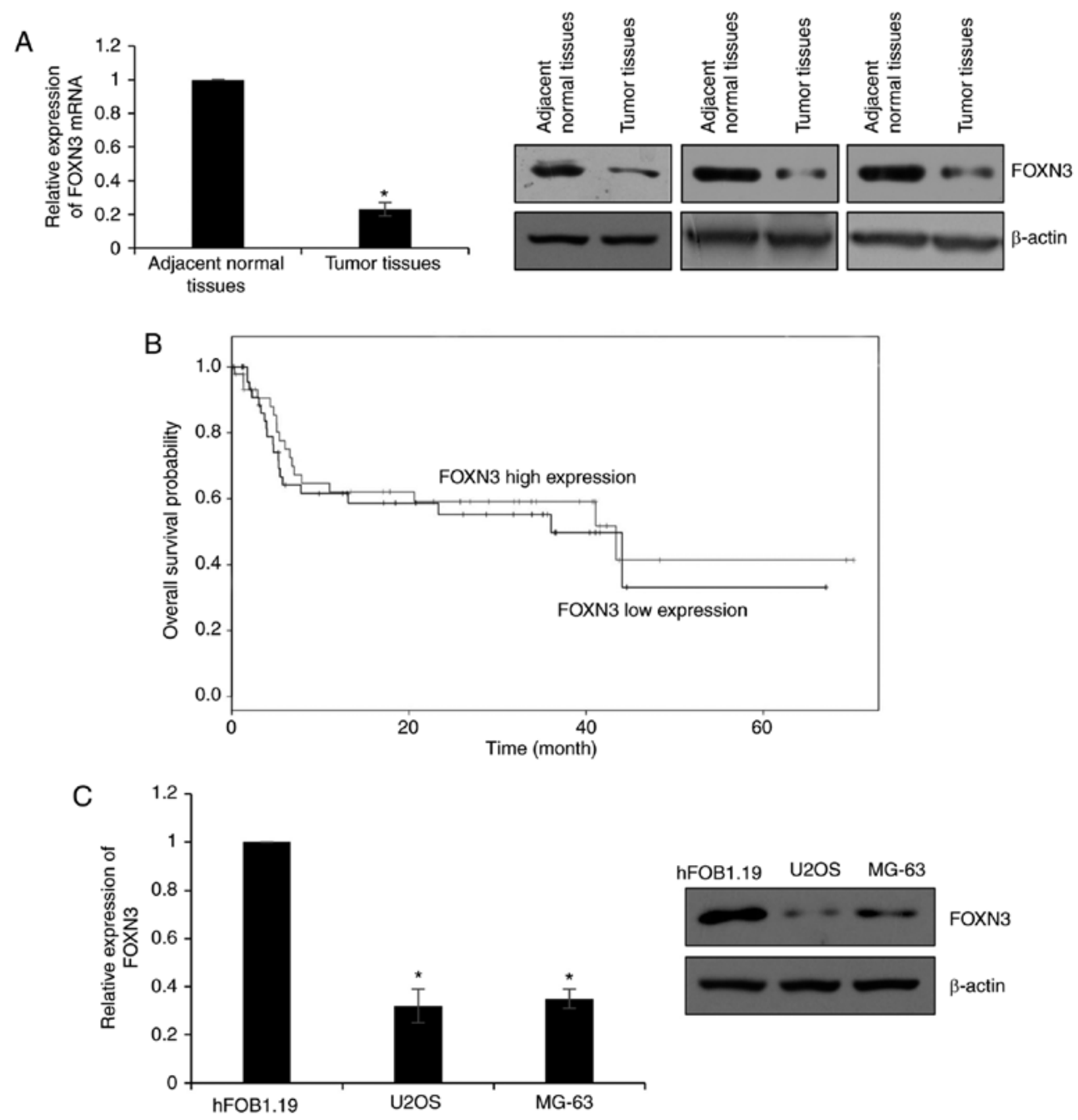

Figure 1. FOXN3 expression is significantly downregulated in OS. (A) RT-qPCR and western blotting were performed to determine the mRNA and protein levels of FOXN3 in the 78 pairs of OS and adjacent normal tissues. Tumor tissues vs. "P $<0.05$ vs. adjacent normal tissues. (B) Kaplan-Meier analysis and a log-rank test were used to analyze survival curves. $\mathrm{P}=0.041$. (C) RT-qPCR and western blot analysis of FOXN3 expression in OS cell lines; the osteoblast cell line hFOB1.19 was used as a control group. "P<0.05 vs. hFOB1.19. FOXN3, forkhead box N3; OS, osteosarcoma; RT-qPCR, reverse transcription-quantitative polymerase chain reaction.

compared with in the vector-transfected group; however, cells transfected with siFOXN3 exhibited significantly decreased expression levels compared with in the siControl group. Additionally, the expression levels of FOXN3 protein were notably increased and decreased in the overexpression and downregulated groups, respectively, compared with in the corresponding controls (Fig. 2A). As of the negative correlation between FOXN3 expression and tumor size reported in the present study, the effects of FOXN3 on cell proliferation were determined via CCK-8 and colony formation assays. The results of the CCK- 8 assay demonstrated that ectopic expression of FOXN3 significantly decreased and knockdown of FOXN3 significantly increased cell proliferation compared with in the vector and siControl groups, respectively (Fig. 2B). Subsequently, a colony formation assay was conducted, which revealed that overexpression of FOXN3 significantly reduced the number of colonies, and knockdown of FOXN3 significantly increased the number of colonies compared with in the corresponding control groups (Fig. 2C). The findings of the present study suggested that FOXN3 inhibits the proliferation of OS cells.
Downregulation of FOXN3 expression promotes the migration and invasion of OS cells. In the present study, the roles of FOXN3 on cell migration and invasion were analyzed. A wound healing assay was performed to determine the effects of FOXN3 on cell migration, which revealed that FOXN3 overexpression significantly suppressed cell migration compared with in the vector group; however, inhibition of FOXN3 expression significantly promoted cell migration compared with in the siControl group (Fig. 3A). In addition, a Transwell invasion assay was conducted to determine the effects of FOXN3 on cell invasion, which demonstrated that FOXN3 overexpression significantly decreased the number of invaded cells compared with in the vector group; however, downregulation of FOXN3 increased the number of invaded cells compared with in the siControl group (Fig. 3B). These data indicated that FOXN3 suppressed the migration and invasion of OS cells.

FOXN3 transcriptionally regulates SIRT6 expression. A recent study reported that SIRT6 contributed to the migration and invasion of OS cells via the ERK1/2/MMP-9 pathway (20); however, the upstream effectors of SIRT6 in OS remains 
A
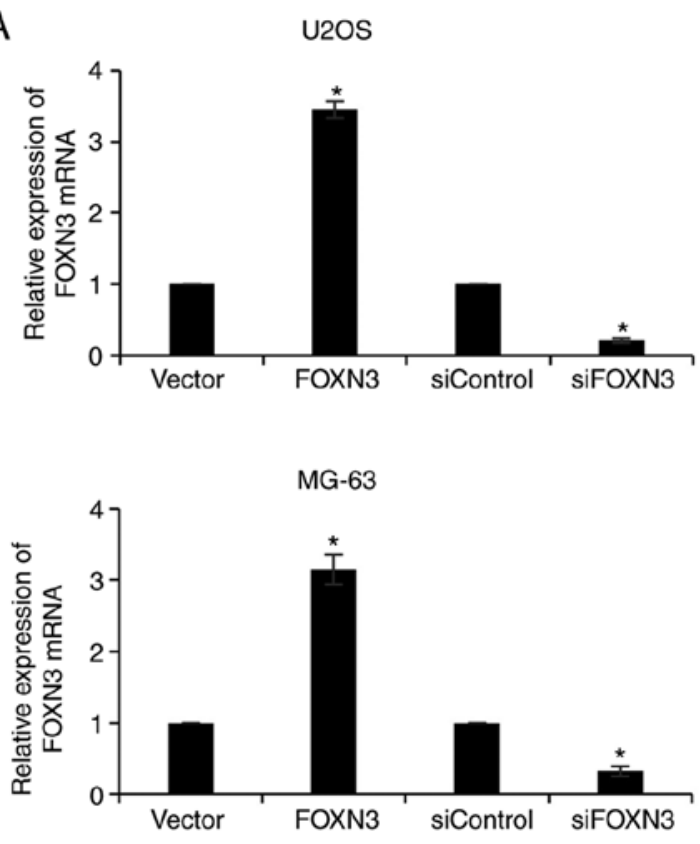

B

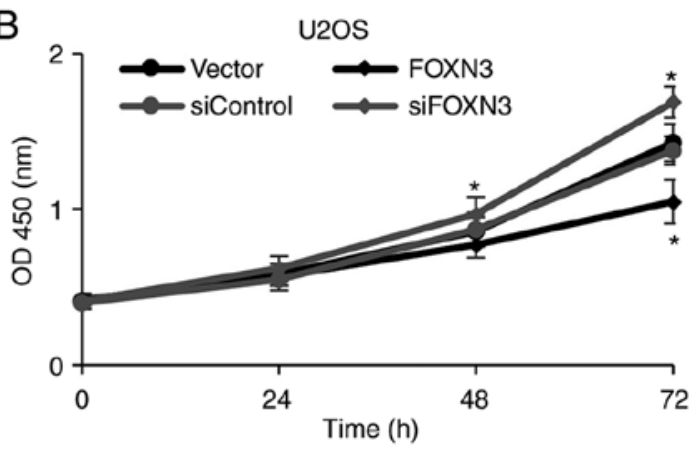

C
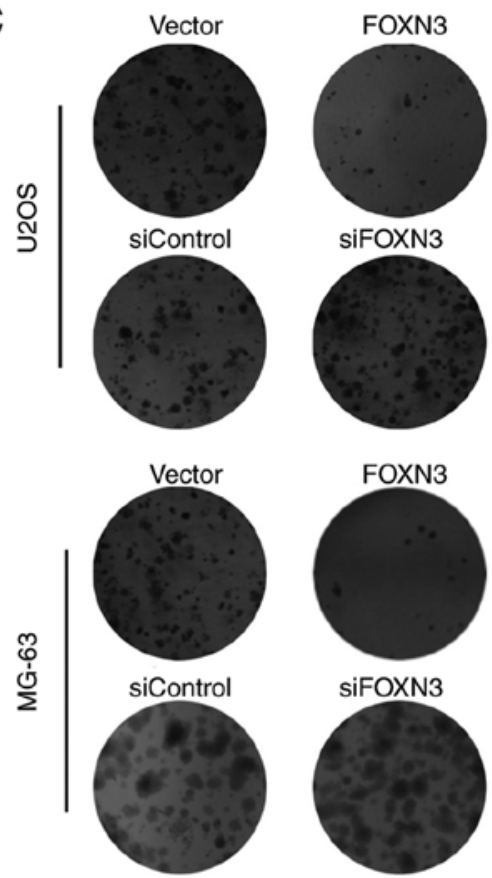

FOXN3

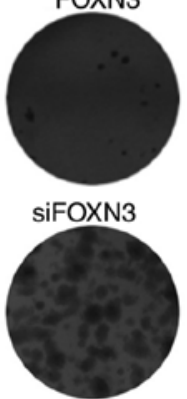

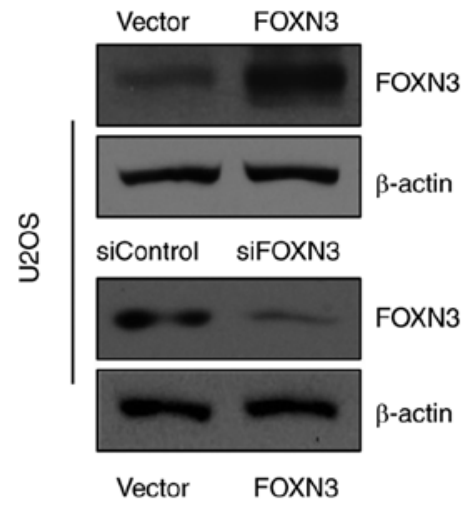
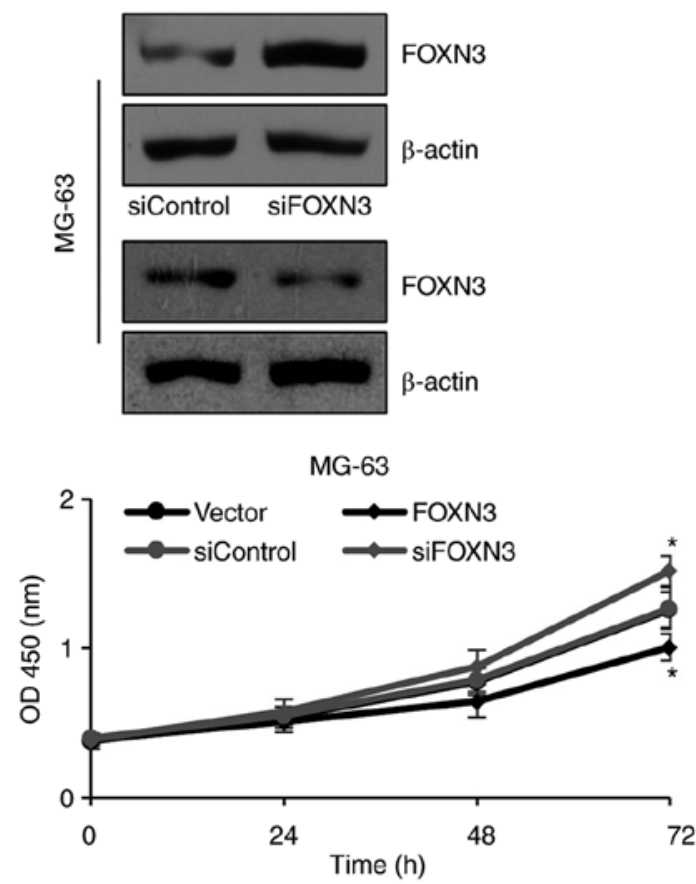

U2OS
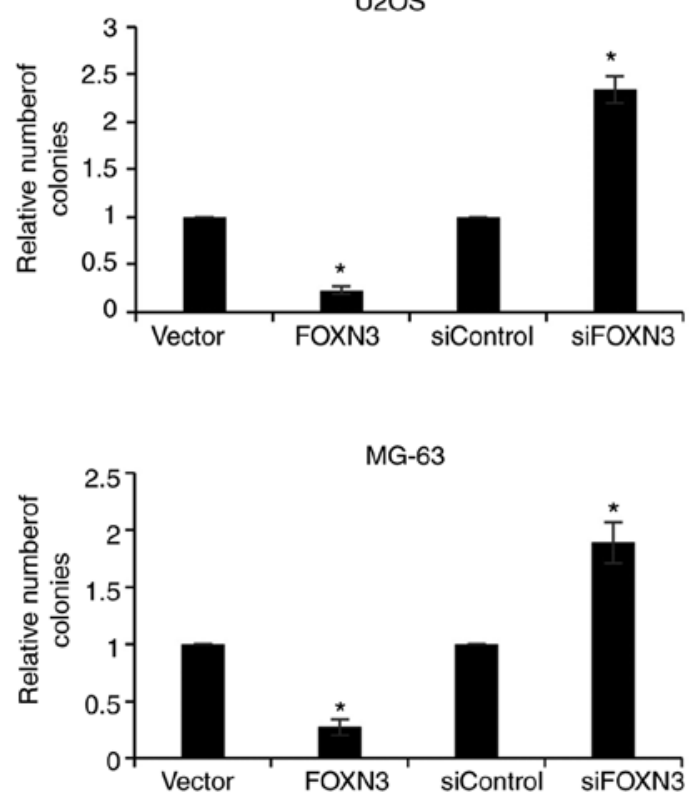

Figure 2. FOXN3 inhibits the proliferation of osteosarcoma cells. (A) Reverse transcription-quantitative polymerase chain reaction and western blot analyses of FOXN3 expression in U2OS or MG-63 cells transfected with vector, FOXN3, siControl, siFOXN3. "P<0.05 FOXN3 vs. vector, siFOXN3 vs. siControl. (B) Effects of FOXN3 on cell proliferation was assessed using a CCK-8 assay. ${ }^{*} \mathrm{P}<0.05$ FOXN3 vs. vector, siFOXN3 vs. siControl. (C) Colony formation assay was performed in U2OS or MG-63 cells transfected with vector, FOXN3 or siControl, siFOXN3 Magnification, x20. "P<0.05 FOXN3 vs. vector, siFOXN3 vs. siControl. FOXN3, forkhead box N3; si, small interfering RNA. 
A
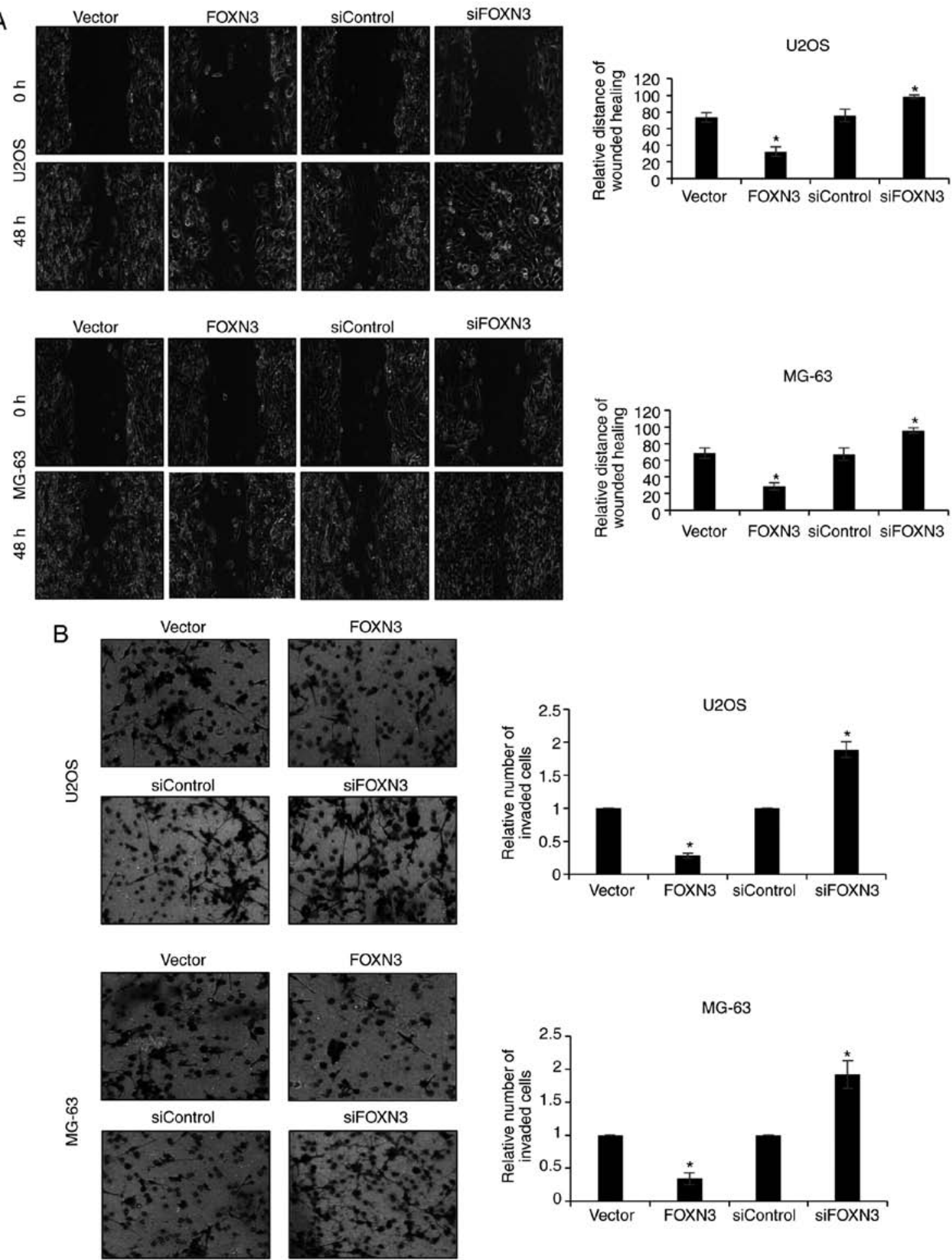

Figure 3. Downregulation of FOXN3 expression promotes the migration and invasion of osteosarcoma cells. (A) U2OS or MG-63 cells were transfected with vector, FOXN3, siControl and siFOXN3, respectively. Following $48 \mathrm{~h}$ post-transfection, a wound healing assay was performed. The relative distance of wound healing was measured under a microscope. ${ }^{*} \mathrm{P}<0.05$ vs. FOXN3 vs. vector, siFOXN3 vs. siControl. Magnification, $\mathrm{x} 20$. (B) FOXN3 was overexpressed or downregulated in U2OS or MG-63 cells. A Transwell invasion assay was performed to detect the effects of FOXN3 on cell invasion. " $\mathrm{P}<0.05$ FOXN3 vs. vector, siFOXN3 vs. siControl. FOXN3 (magnification, x20), forkhead box N3; si, small interfering RNA.

unknown. In order to determine whether FOXN3 regulates SIRT6 expression, FOXN3 expression was upregulated or silenced in U2OS and MG-63 cells, RT-qPCR and western blot analyses were conducted. The results revealed that the expression levels of SIRT6 mRNA were significantly downregulated when FOXN3 was overexpressed compared with in the vector group; FOXN3 silencing significantly increased the expression of SIRT6 compared with in the siControl group (Fig. 4A). Additionally, ChIP and qChIP assays were performed, which revealed that FOXN3 may bind the promoter region of SIRT6 in U2OS and MG-63 cells; E2F5 was used as a positive control (9) (Fig. 4B). Additionally, the results of the dual 
A
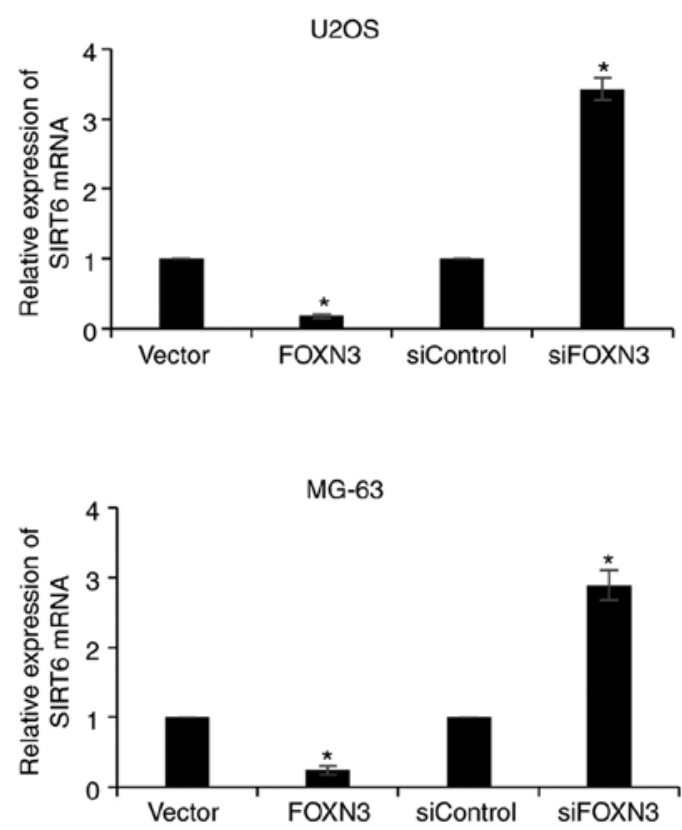
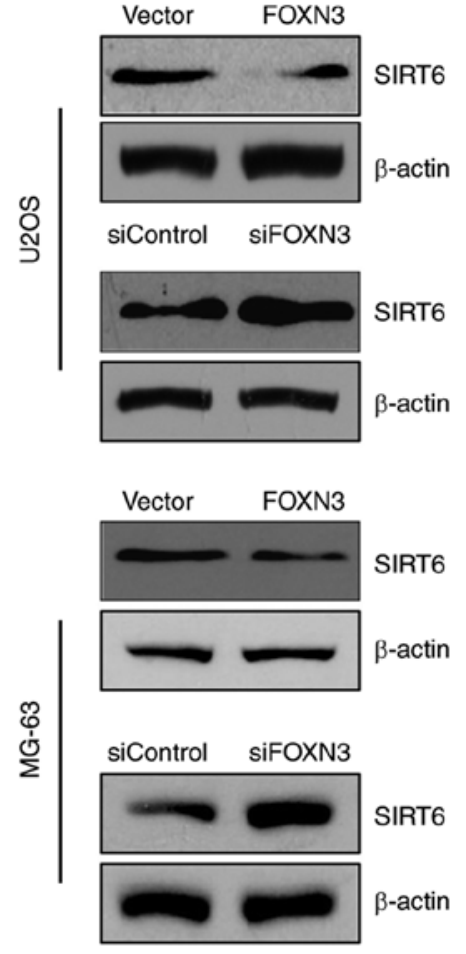

B

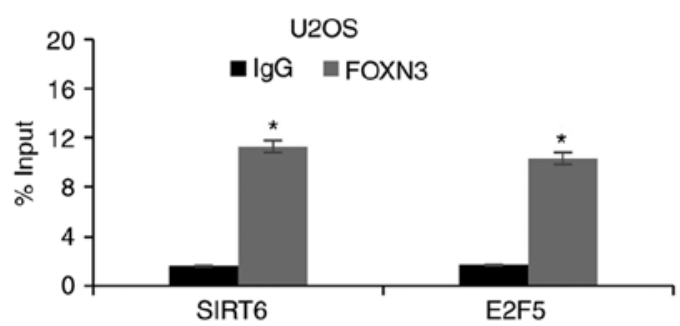

C

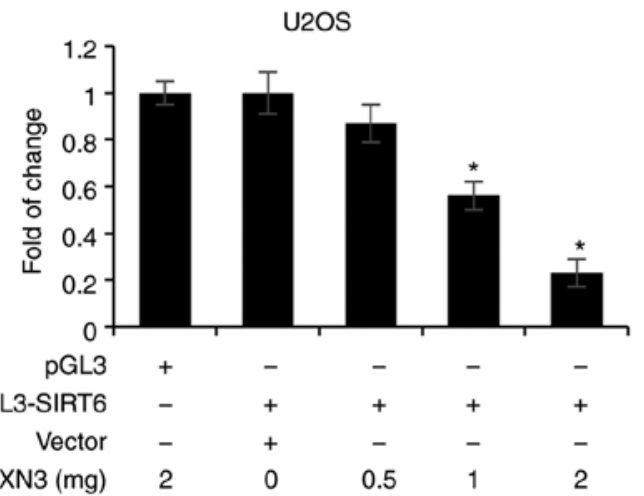

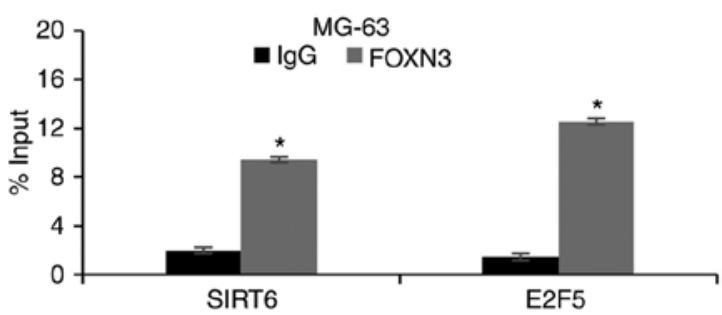

MG-63

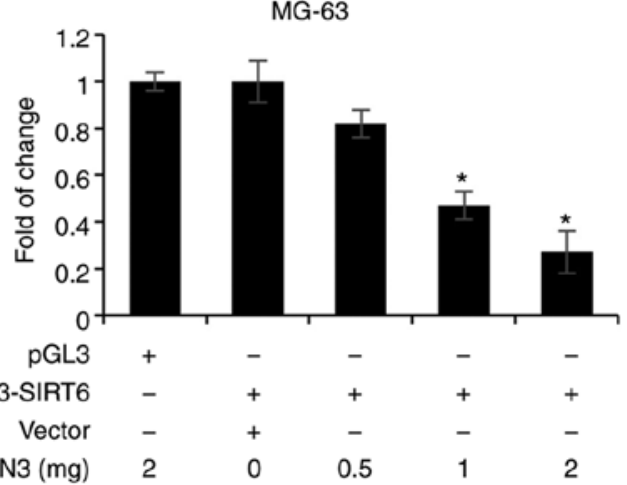

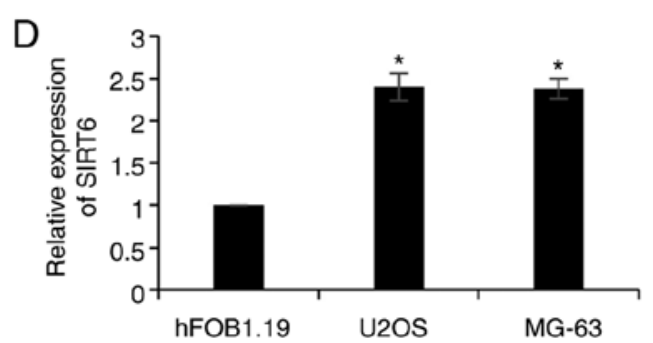

Figure 4. FOXN3 transcriptionally regulates SIRT6 expression. (A) U2OS or MG-63 cells were transfected with vector, FOXN3, siControl or siFOXN3, respectively. After $48 \mathrm{~h}$ post-transfection, the expression of SIRT6 was detected by RT-qPCR and western blotting. * $\mathrm{P}<0.05$ FOXN3 vs. vector, siFOXN3 vs. siControl. (B) Binding of FOXN3 to the SIRT6 promoter in U2OS or MG-63 cells was analyzed by ChIP and quantitative ChIP assays using antibodies to FOXN3 and IgG, and RT-qPCR was used to analyze the SIRT6 promoter. E2F5 was used as a positive control. *P<0.05 vs. IgG. (C) Activity of the SIRT6 promoter following transfection of FOXN3 into U2OS or MG-63 cells was detected via a luciferase reporter assay. ${ }^{*} \mathrm{P}<0.05$ vs. vector + pGL3-SIRT6. (D) RT-qPCR analysis of SIRT6 expression in osteosarcoma cell lines and the osteoblast cell line, hFOB1.19, which was used as a control group. *P<0.05 vs. hFOB1.19. ChIP, chromatin immunoprecipitation; FOXN3, forkhead box N3; RT-qPCR, reverse transcription-quantitative polymerase chain reaction; si, small interfering RNA. 
A
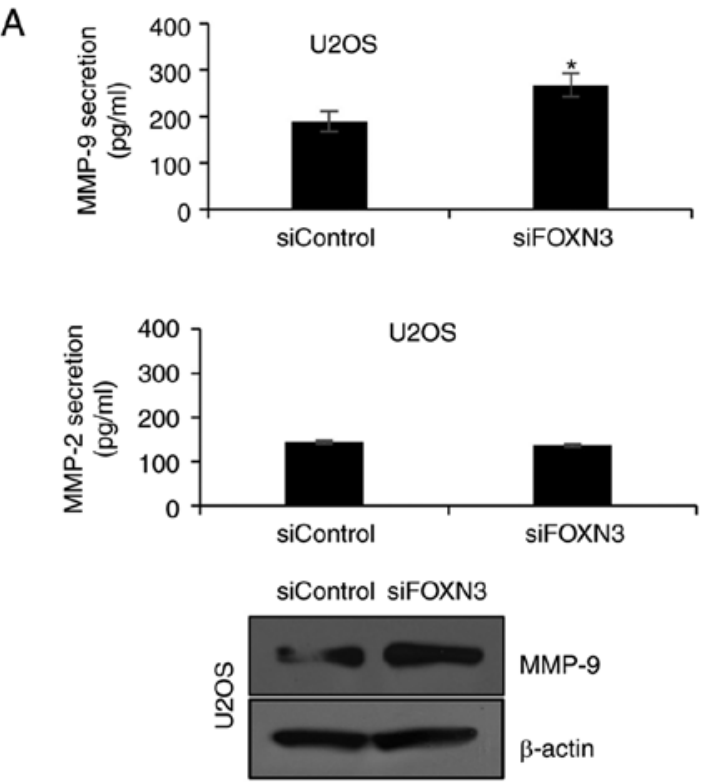

$\mathrm{B}$
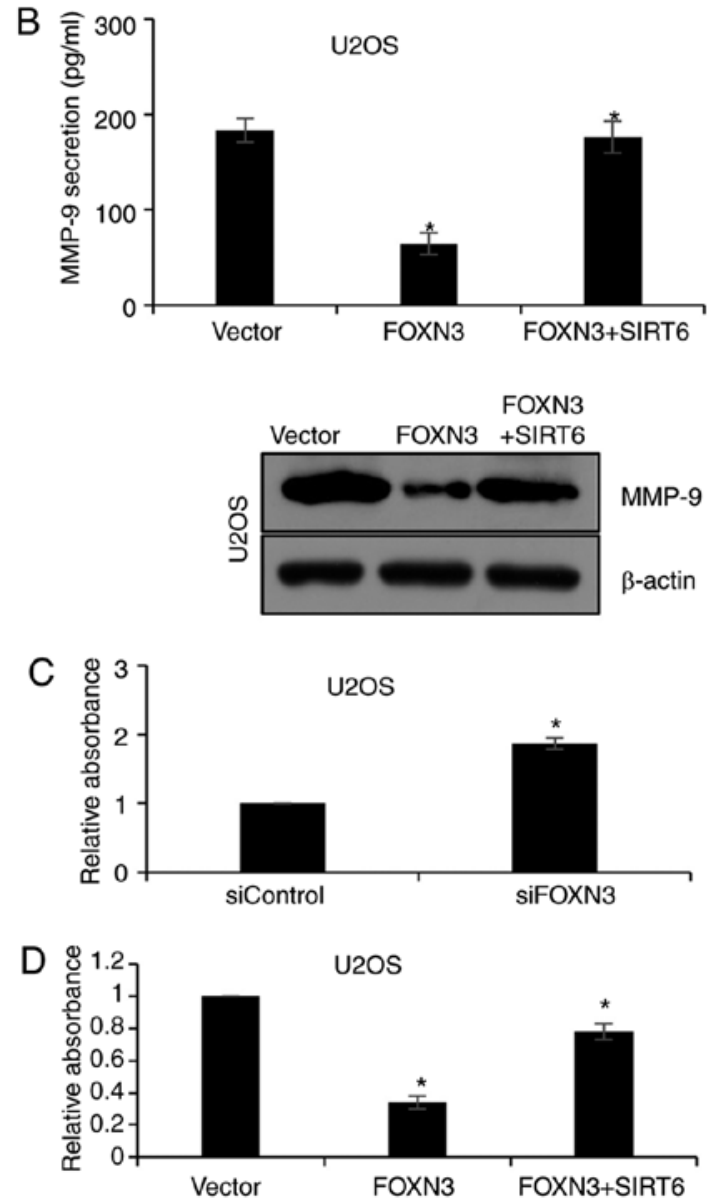
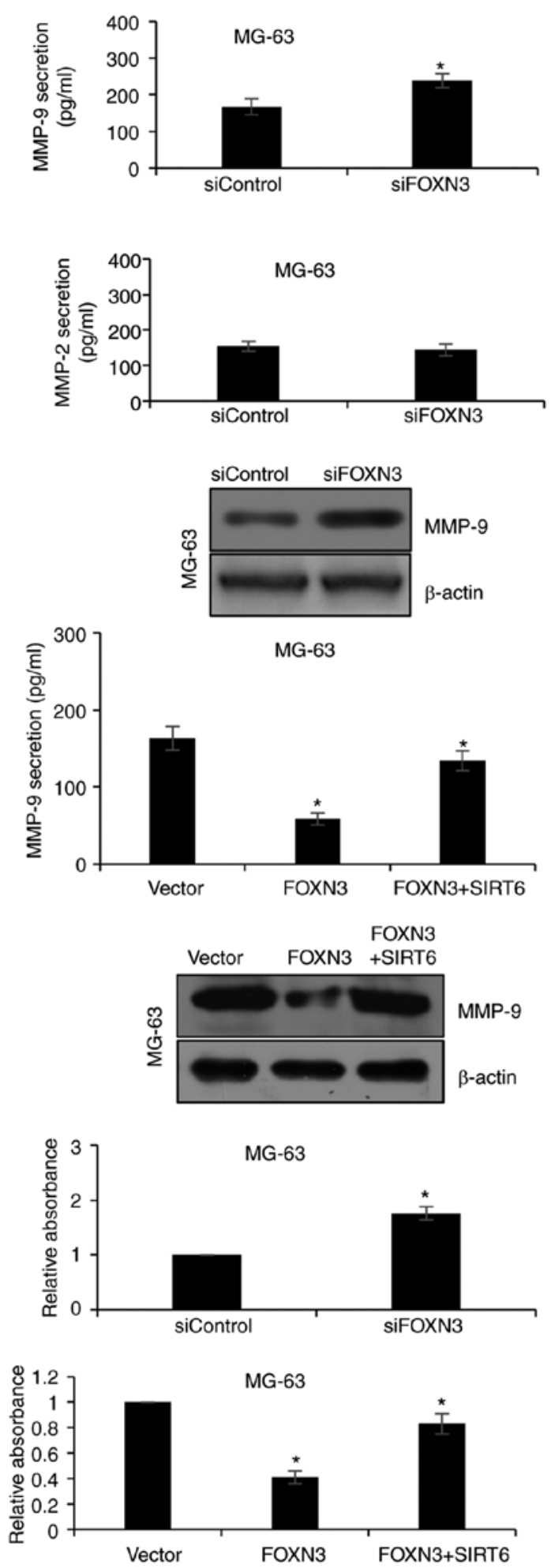

Figure 5. FOXN3 suppresses MMP-9 secretion via the regulation of SIRT6 expression. (A) FOXN3 was downregulated in U2OS or MG-63 cells; MMP-9 or MMP-2 secretion was detected using MMP-9 and MMP-2 ELISA kits. "P $<0.05$ vs. siControl. The expression of MMP-9 was determined via western blotting. (B) U2OS or MG-63 cells were transfected with FOXN3, in the presence or absence of SIRT6 overexpression. The secretion of MMP-9 was detected using an MMP-9 ELISA kit. "P<0.05 FOXN3 vs. vector, FOXN3 + SIRT6 vs. FOXN3. The expression of MMP-9 was determined via western blotting. (C) FOXN3 was downregulated in U2OS or MG-63 cells; zymography experiments were performed in triplicate, quantified and analyzed via a Student's t-test. "P<0.05 vs. siControl. (D) U2OS or MG-63 cells were transfected with FOXN3, in the presence or absence of SIRT6 overexpression. Zymography experiments were performed in triplicate, quantified and analyzed via analysis of variance. " $\mathrm{P}<0.05$ FOXN3 vs. vector, FOXN3 + SIRT6 vs. FOXN3. FOXN3, forkhead box N3; si, small interfering RNA; SIRT6, sirtuin 6.

luciferase reporter assay suggested that FOXN3 significantly suppressed SIRT6 expression via transcription compared with in vector-transfected cells (Fig. 4C). In addition, the expression of SIRT6 in U2OS and MG-63 OS cells, and the osteoblast cell line, hFOB1.19 were determined. The results revealed that SIRT6 expression was significantly upregulated 
in U2OS and MG-63 cells compared with in hFOB1.19 cells (Fig. 4D). Furthermore, the expression of SIRT6 in OS tissues was negatively correlated with FOXN3 expression (Table I; $\mathrm{P}<0.05)$. Collectively, the expression of SIRT6 was proposed to be regulated by FOXN3 in OS.

FOXN3 suppresses MMP-9 secretion via the regulation of SIRT6 expression. MMP-9 can digest gelatins or denatured collagens (24), and has been reported to promote metastasis in some types of cancers $(25,26)$. In addition, SIRT6 was proposed to regulate MMP-9 expression in OS and non-small cell lung cancer (27). As FOXN3 was determined to regulate SIRT6 expression in the present study, it was hypothesized that FOXN3 may also regulate MMP-9 secretion. The results of ELISA demonstrated that FOXN3 knockdown significantly increased the secretion levels of MMP-9 in U2OS and MG-63 cells compared with in the siControl group; FOXN3 silencing was observed to have no notable effect on MMP-2 secretion (Fig. 5A). FOXN3 overexpression significantly reduced the secretion levels of MMP-9 in U2OS and MG-63 cells compared with in the vector group (Fig. 5B), which were significantly reversed when cells simultaneously overexpressed FOXN3 and SIRT6 (Fig. 5B). Furthermore, the gelatin zymography assay demonstrated that FOXN3 significantly suppressed MMP-9 secretion compared with in the vector group, which was reversed following overexpression of SIRT6 (Fig. 5C and D). The findings of the present study demonstrated that FOXN3 may suppresses MMP-9 secretion via the regulation of SIRT6.

\section{Discussion}

At present, the biological roles of FOXN3 are still poorly understood. Numerous studies have demonstrated the physiological roles of FOXN3 in the craniofacial development of mouse and eye development of xenopus laevis $(28,29)$. FOXN3 has been reported to be downregulated in HCC and other cancer types (9); however, the roles of FOXN3 in OS require further investigation.

In the present study, the expression pattern of FOXN3 in OS was analyzed. Downregulation of FOXN3 expression in OS tissues was observed at the mRNA and protein levels, which suggested that FOXN3 expression may be a novel diagnostic marker of OS. Additionally, FOXN3 was also downregulated in the OS cell lines, U2OS and MG-63, compared with in the osteoblast cell line, hFOB1.19. The expression of FOXN3 was negatively correlated with tumor size and metastasis, as well as TNM stage, suggesting that FOXN3 may serve as a tumor suppressor in OS. Furthermore, low expression of FOXN3 may predict a poor prognosis for patients with OS.

A recent study revealed that FOXN3 inhibited the proliferation of HCC cells (9). In the present study, numerous functional experiments, including colony formation and CCK-8 assays were performed, which revealed that FOXN3 also suppressed the proliferation of OS cells. In addition, wound healing and Transwell invasion assays also suggested that FOXN3 inhibited the migration and invasive abilities of OS cells.

A recent study proposed that SIRT6 was overexpressed in OS tissues and cell lines (20). SIRT6 facilitated the migration and invasion of OS cells (20); however, the upstream effectors of SIRT6 in OS have not yet been reported. The present study demonstrated that FOXN3 could regulate SIRT6 expression at the mRNA and protein levels, which suggested that FOXN3 may transcriptionally regulate SIRT6 expression. Subsequently, ChIP and qChIP, as well as a luciferase reporter assay suggested that SIRT6 was transcriptionally regulated by FOXN3. In addition, the secretion of MMP-9 was suppressed by FOXN3, which may occur via the regulation of SIRT6.

However, there are limitations to the present study. Firstly, the expression of FOXN3 in OS tissues should be detected via immunohistochemistry staining. Additionally, experiments should be performed to determine whether FOXN3 suppresses the migration and invasion of OS cells in vivo. Furthermore, it is necessary to determine the upstream effectors of FOXN3 in OS. A previous report indicated that the Wnt signaling pathway could reduce FOXN3 expression (30). In addition, the Wnt/ $\beta$-catenin signaling pathway was reported to be activated in OS tissues and cells, and aberrant activation may serve a central role in the tumorigenesis, metastasis and chemotherapeutic responses of OS $(31,32)$. Numerous reports have revealed that microRNAs regulate the Wnt signaling pathway in OS (33-35), indicating that microRNAs may be the upstream molecules involved in FOXN3 signaling.

In summary, the present study revealed that FOXN3 may serve as a tumor suppressor in OS and that FOXN3 may be considered as a novel prognostic predictor and therapeutic target for the treatment of OS.

\section{Acknowledgements}

Not applicable.

\section{Funding}

No funding was received.

\section{Availability of data and materials}

The datasets used during the present study are available from the corresponding author upon reasonable request.

\section{Authors' contributions}

WX, XZ and WZ conceived and designed the work. WX, LM, and $\mathrm{ZW}$ constructed expression plasmids, prepared proteins and performed experiments. WX and LM analyzed the data. WX, WZ and XZ wrote the paper. All authors read and approved the final manuscript.

\section{Ethics approval and consent to participate}

The present study was approved by the Research Ethics Committee of Yidu Central Hospital of Weifang (LK2017012, Weifang, China). All patients had provided written informed consent.

\section{Patient consent for publication}

Not applicable. 


\section{Competing interests}

The authors declare that they have no competing interests.

\section{References}

1. Bielack S, Carrle D, Casali PG and ESMO Guidelines Working Group: Osteosarcoma: ESMO clinical recommendations for diagnosis, treatment and follow-up. Ann Oncol 4 (Suppl 20): S137-S139, 2009.

2. Damron TA, Ward WG and Stewart A: Osteosarcoma, chondrosarcoma, and Ewing's sarcoma: National cancer data base report. Clin Orthop Relat Res 459: 40-47, 2007.

3. Ottaviani $\mathrm{G}$ and Jaffe N: The epidemiology of osteosarcoma. Cancer Treat Res 152: 3-13, 2009.

4. Tan ML, Choong PF and Dass CR: Osteosarcoma: Conventional treatment vs. gene therapy. Cancer Biol Ther 8: 106-117, 2009.

5. Bacci G, Briccoli A, Rocca M, Ferrari S, Donati D, Longhi A, Bertoni F, Bacchini P, Giacomini S, Forni C, et al: Neoadjuvant chemotherapy for osteosarcoma of the extremities with metastases at presentation: Recent experience at the Rizzoli Institute in 57 patients treated with cisplatin, doxorubicin, and a high dose of methotrexate and ifosfamide. Ann Oncol 14: 1126-1134, 2003.

6. Rainusso N, Wang LL and Yustein JT: The adolescent and young adult with cancer: State of the art-bone tumors. Curr Oncol Rep 15: 296-307, 2013.

7. Bielack SS, Kempf-Bielack B, Delling G, Exner GU, Flege S, Helmke K, Kotz R, Salzer-Kuntschik M, Werner M, Winkelmann W, et al: Prognostic factors in high-grade osteosarcoma of the extremities or trunk: An analysis of 1,702 patients treated on neoadjuvant cooperative osteosarcoma study group protocols. J Clin Oncol 20: 776-790, 2002.

8. Scott KL and Plon SE: CHES1/FOXN3 interacts with Ski-interacting protein and acts as a transcriptional repressor. Gene 359: 119-126, 2005.

9. Sun J, Li H, Huo Q, Cui M, Ge C, Zhao F, Tian H, Chen T, Yao M and $\mathrm{Li}$ J: The transcription factor FOXN3 inhibits cell proliferation by downregulating E2F5 expression in hepatocellular carcinoma cells. Oncotarget 7: 43534-43545, 2016.

10. Balciunaite G, Keller MP, Balciunaite E, Piali L, Zuklys S, Mathieu YD, Gill J, Boyd R, Sussman DJ and Holländer GA: Wnt glycoproteins regulate the expression of FoxN1, the gene defective in nude mice. Nat Immunol 3: 1102-1108, 2002.

11. LiC,Lusis AJ,Sparkes R, Tran SM and Gaynor R: Characterization and chromosomal mapping of the gene encoding the cellular DNA binding protein HTLF. Genomics 13: 658-664, 1992.

12. Chang JT, Wang HM, Chang KW, Chen WH, Wen MC, Hsu YM, Yung BY, Chen IH, Liao CT, Hsieh LL and Cheng AJ Identification of differentially expressed genes in oral squamous cell carcinoma (OSCC): Overexpression of NPM, CDK1 and NDRG1 and underexpression of CHES1. Int J Cancer 114: 942-949, 2005

13. Markowski J, Tyszkiewicz T, Jarzab M, Oczko-Wojciechowska M, Gierek T, Witkowska M, Paluch J, Kowalska M, Wygoda Z, Lange D and Jarzab B: Metal-proteinase ADAM12, kinesin 14 and checkpoint suppressor 1 as new molecular markers of laryngeal carcinoma. Eur Arch Otorhinolaryngol 266: 1501-1507, 2009.

14. Li S, Mo Z, Yang X, Price SM, Shen MM and Xiang M: Foxn4 controls the genesis of amacrine and horizontal cells by retinal progenitors. Neuron 43: 795-807, 2004.

15. Katoh M: Identification and characterization of human FOXN5 and rat Foxn5 genes in silico. Int J Oncol 24: 1339-1344, 2004.

16. Wang X, He B, Gao Y and Li Y: FOXR2 contributes to cell proliferation and malignancy in human hepatocellular carcinoma. Tumour Biol 37: 10459-10467, 2016.
17. Huot G, Vernier M, Bourdeau V, Doucet L, Saint-Germain E, Gaumont-Leclerc MF, Moro A and Ferbeyre G: CHES1/FOXN3 regulates cell proliferation by repressing PIM2 and protein biosynthesis. Mol Biol Cell 25: 554-565, 2014.

18. Gertler AA and Cohen HY: SIRT6, a protein with many faces. Biogerontology 14: 629-639, 2013.

19. Kim HS, Xiao C, Wang RH, Lahusen T, Xu X, Vassilopoulos A, Vazquez-Ortiz G, Jeong WI, Park O, Ki SH, et al: Hepatic-specific disruption of SIRT6 in mice results in fatty liver formation due to enhanced glycolysis and triglyceride synthesis. Cell Metab 12: 224-236, 2010.

20. Lin H, Hao Y, Zhao Z and Tong Y: Sirtuin 6 contributes to migration and invasion of osteosarcoma cells via the ERK1/2/MMP9 pathway. FEBS Open Bio 7: 1291-1301, 2017.

21. Baumhoer D: Pathogenesis and genetics of osteosarcoma: Current concepts and developments. Der Pathologe 39: 139-145, 2018 (In German).

22. Livak KJ and Schmittgen TD: Analysis of relative gene expression data using real-time quantitative PCR and the 2(-Delta Delta C(T)) method. Methods 25: 402-408, 2001

23. Descamps FJ, Martens E and Opdenakker G: Analysis of gelatinases in complex biological fluids and tissue extracts. Lab Invest 82: 1607-1608, 2002.

24. Padala C, Tupurani MA, Puranam K, Gantala S, Shyamala N, Kondapalli MS, Gundapaneni KK, Mudigonda S, Galimudi RK, Kupsal K, et al: Synergistic effect of collagenase-1 (MMP1), stromelysin-1 (MMP3) and gelatinase-B (MMP9) gene polymorphisms in breast cancer. PLoS One 12: e0184448, 2017.

25. Cai X, Zhu H and Li Y: PKCzeta, MMP2 and MMP9 expression in lung adenocarcinoma and association with a metastatic phenotype. Mol Med Rep 16: 8301-8306, 2017.

26. Jia ZH, Jia Y, Guo FJ, Chen J, Zhang XW and Cui MH: Phosphorylation of STAT3 at Tyr705 regulates MMP-9 production in epithelial ovarian cancer. PLoS One 12: e0183622, 2017.

27. Bai L, Lin G, Sun L, Liu Y, Huang X, Cao C, Guo Y and Xie C: Upregulation of SIRT6 predicts poor prognosis and promotes metastasis of non-small cell lung cancer via the ERK1/2/MMP9 pathway. Oncotarget 7: 40377-40386, 2016.

28. Schuff M, Rossner A, Wacker SA, Donow C, Gessert S and Knochel W: FoxN3 is required for craniofacial and eye development of Xenopus laevis. Dev Dyn 236: 226-239, 2007.

29. Samaan G, Yugo D, Rajagopalan S, Wall J, Donnell R, Goldowitz D, Gopalakrishnan R and Venkatachalam S: Foxn3 is essential for craniofacial development in mice and a putative candidate involved in human congenital craniofacial defects. Biochem Biophys Res Commun 400: 60-65, 2010.

30. Nagel S, Meyer C, Kaufmann M, Drexler HG and MacLeod RA: Deregulated FOX genes in Hodgkin lymphoma. Genes Chromosomes Cancer 53: 917-933, 2014.

31. Cai Y, Mohseny AB, Karperien M, Hogendoorn PC, Zhou G and Cleton-Jansen AM: Inactive Wnt/beta-catenin pathway in conventional high-grade osteosarcoma. J Pathol 220: 24-33, 2010.

32. Hendrix ND, Wu R, Kuick R, Schwartz DR, Fearon ER and Cho KR: Fibroblast growth factor 9 has oncogenic activity and is a downstream target of Wnt signaling in ovarian endometrioid adenocarcinomas. Cancer Res 66: 1354-1362, 2006.

33. Du Z, Li F, Wang L, Huang $\mathrm{H}$ and Xu S: Regulatory effects of microRNA184 on osteosarcoma via the $\mathrm{Wnt} / \beta$-catenin signaling pathway. Mol Med Rep 18: 1917-1924, 2018.

34. Zhao X, Sun S, Xu J, Luo Y, Xin Y and Wang Y: MicroRNA-152 inhibits cell proliferation of osteosarcoma by directly targeting Wnt/ $\beta$-catenin signaling pathway in a DKK1-dependent manner. Oncol Rep 40: 767-774, 2018.

35. Yu M, Guo D, Cao Z, Xiao L and Wang G: Inhibitory effect of microRNA-107 on osteosarcoma malignancy through regulation of $\mathrm{Wnt} / \beta$-catenin signaling in vitro. Cancer Invest 36: 175-184, 2018. 